\title{
Tuberculous brain abscess in a child with tetralogy of Fallot
}

Sir,

A two-year-old boy, a known case of tetralogy of Fallot (TOF), presented with fever and projectile vomiting of 15 days duration. There was no history of seizures, ear discharge, or altered sensorium. No history of contact with tuberculosis. On examination, his vital signs were stable. His weight was $10 \mathrm{~kg}$ and height was $85 \mathrm{~cm}$. He was plethoric with central cyanosis and grade II clubbing. He had a BCG scar. Cardiovascular system examination revealed a single second heart sound and ejection systolic murmur in the pulmonary area. Ocular fundi were normal. Neurological examination was otherwise normal, except for neck stiffness and bilateral plantar extensor.

Investigations revealed: Hemoglobin $15.8 \mathrm{gm} / \mathrm{dL}$, total WBC count 15600 cells cu.mm with differential of neutrophils $68 \%$ and lymphocytes $25 \%$. Mantoux test and HIV ELISA were negative. Echocardiogram did not reveal any vegetation. Chest $X$-ray was within normal limits. CT brain demonstrated two brain abscess measuring $3 \times 3.5 \mathrm{~cm}$ in the left fronto-parietal region with perilesional edema and mass effect [Figure 1]. A left parietal burr hole was made and $15 \mathrm{ml}$ of pus was aspirated from a depth of $1.5 \mathrm{~cm}$ from the cortical surface. Cefotaxime, metronidazole, and cloxacillin were instituted initially. Gram stain of pus did not reveal any organism and aerobic culture was sterile.

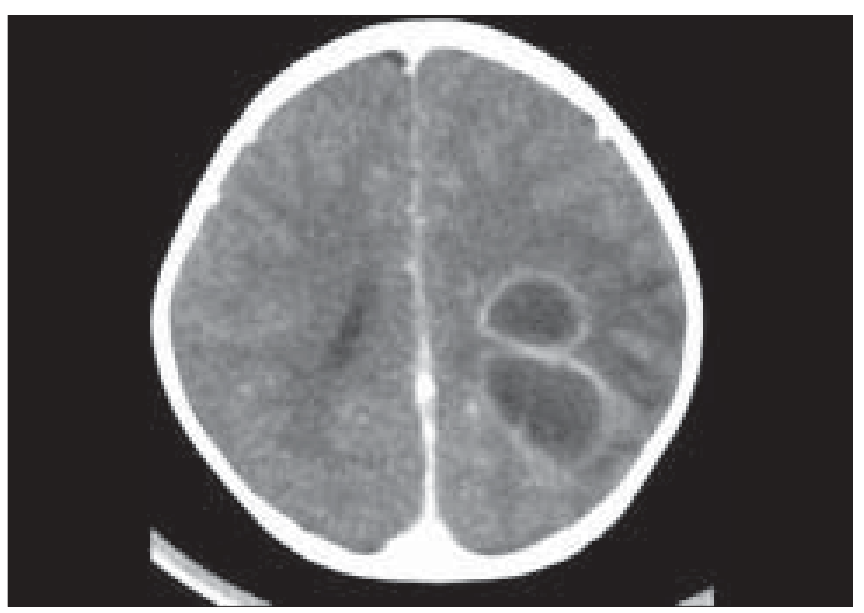

Figure 1: Computed tomography of the brain in a child with tetralogy of Fallot demonstrating two brain abscess in left fronto-parietal region 
Zeil Neilson smear did not show acid fast bacilli. He was treated with parenteral antibiotics for two weeks and discharged on oral cloxacillin after he improved symptomatically. Surprisingly, after six weeks, his pus grew mycobacterium tuberculosis sensitive to isoniazid, rifampicin, pyrazinamide, and ethambutol. He was started on isoniazid, rifampicin, pyrazinamide, and ethambutol. Unfortunately, he was lost to follow up after this and the outcome of the illness is not known.

Brain abscess in patients with cyanotic heart disease constitutes $11 \%$ of all brain abscesses and the incidence is in decline in developed countries due to early surgical interventions in patients with congenital heart diseases ${ }^{[1]}$ Tuberculoma of brain is an extremely uncommon lesion in patients with cyanotic heart diease. Moorthy et al. ${ }^{[2]}$ reported brainstem tuberculoma in an adult patient with cyanotic heart disease Ray et al., ${ }^{[3]}$ reported tuberculoma in a child with congenital heart diseases. Probably this is the first report of tuberculous brain abscess in a patient with cyanotic heart disease. Antituberculous therapy and surgical intervention are the mainstays of management.

We report this case since physicians treating children with congenital heart lesions should be aware of this rare association and consider when there is inadequate response to initial broad-spectrum antibiotics.

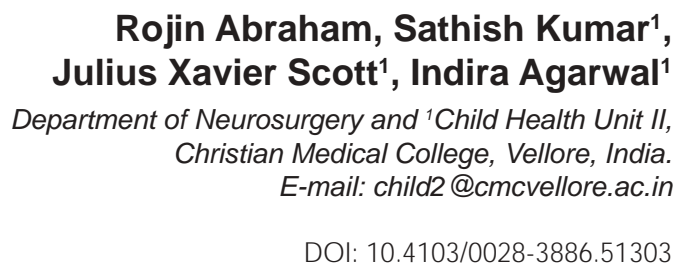

\section{References}

1. Mamoalam TJ, Rosenblum ML. Trends in the management of bacterial brain abscesses: A review of 102 cases over 17 years. Neurosurgery 1988;23:451-8.

2. Moorthy RK, Rajshekhar V. Isolated ring-enhancing lesion of the brainstem in a patient with cyanotic heart disease: Role of stereotactic intervention. Neurol India 2003;51:404-6.

3. Ray D, Menon RK, Menon PS, Gupta G, Shrivastava S, Tandon R. Hypertrophic osteoarthropathy, tuberculoma of brain and cyanotic heart disease. Indian J Pediatr 1988;55:304-7.

Accepted on 31-03-2009 